\title{
rubenEfeitos da incorporação de resíduos de construção e demolição na aderência de argamassas de revestimento
}

A reciclagem dos resíduos de construção e demolição $(R C D)$ é uma solução para a conservação dos recursos naturais não renováveis extraídos pelo setor da construção civil, além de contribuir para a redução de custos e impactos ambientais. O RCD pode ser utilizado na forma de agregados reciclados, em substituição parcial ou total aos agregados naturais utilizados em concretos e argamassas, a fim de atender às necessidades da indústria da construção. No que se refere às argamassas de revestimento, a principal propriedade que deve ser avaliada é a aderência com o substrato. Sendo assim, o objetivo deste trabalho foi avaliar os efeitos da substituição do agregado miúdo por agregado reciclado na consistência e resistência de aderência à tração de argamassas mistas de revestimento. As amostras de RCD foram coletadas em um terreno baldio na cidade de Porto Nacional (TO), sendo, em seguida, classificadas e moídas. Ensaios de caracterização foram realizados com o objetivo de permitir a utilização do material como agregado miúdo. Os resultados do ensaio de resistência de aderência, obtidos para diferentes tipos de agregado reciclado (cerâmico, cimentício e mistura de ambos), foram comparados, de modo a determinar o desempenho das diferentes argamassas avaliadas. A metodologia utilizada seguiu os procedimentos definidos pelas normas da ABNT.

Palavras-chave: RCD; Argamassas; Revestimento; Aderência.

\section{Effects of incorporation of construction and demolition residues on the adhesion of coating mortars}

\begin{abstract}
The recycling of construction and demolition waste $(\mathrm{RCD})$ is a solution for the conservation of non-renewable natural resources extracted by the construction sector, besides contributing to the reduction of costs and environmental impacts. RCD can be used in the form of recycled aggregates, in partial or total replacement to natural aggregates used in concrete and mortar to meet the needs of the construction industry. With regard to coating mortars, the main property to be evaluated is the adhesion with the substrate. Thus, the objective of this work was to evaluate the effects of replacing the small aggregate by recycled aggregate on the consistency and tensile strength of mixed coating mortars. The RCD samples were collected in a vacant lot in the city of Porto Nacional (TO), then classified and ground. Characterization tests were carried out in order to allow the use of the material as minute aggregate. The results of the bond strength test, obtained for different types of recycled aggregate (ceramic, cement and mixture of both), were compared in order to determine the performance of the different mortars evaluated. The methodology used followed the procedures defined by ABNT standards.
\end{abstract}

Keywords: RCD; Mortars; Coating; Grip.

Topic: Engenharia de Materiais

Reviewed anonymously in the process of blind peer
Received: 18/01/2019

Approved: 19/03/2019
Jordania dos Santos Rocha

Instituto Tocantinense Presidente Antônio Carlos Porto, Brasil http://lattes.cnpq.br/1176589666510539

jordania326@gmail.com

Taís Gomes

Instituto Tocantinense Presidente Antônio Carlos Porto, Brasil http://lattes.cnpq.br/4299624774874461

tais.go3@gmail.com

Ericles Bruno Muniz Novais (iD

Instituto Tocantinense Presidente Antônio Carlos Porto, Brasil http://lattes.cnpq.br/6181125172616043

http://orcid.org/0000-0002-2612-981X

brunonovais9595@hotmail.com
Francisco Adriano Rodrigues Duarte

Instituto Tocantinense Presidente Antônio Carlos Porto, Brasil

http://lattes.cnpq.br/9009681375552369

fran.adriano20@gmail.com
Referencing this:

ROCHA, J. S.; GOMES, T.; NOVAIS, E. B. M.; DUARTE, F. A. R.. Efeitos da incorporação de resíduos de construção e demolição na aderência de argamassas de revestimento. Engineering Sciences, v.7, n.1, p.81-92, 2019. DOI: http://doi.org/10.6008/CBPC2318-3055.2019.001.0009 


\section{INTRODUÇÃO}

A cadeia produtiva da construção civil gera impactos ambientais significativos em todas as etapas do seu processo, desde a extração de matérias-primas, produção de materiais, execução da obra, uso e, futuramente, no processo de demolição. $O$ esgotamento dos recursos naturais e a poluição, através da geração de resíduos, podem ser considerados como os impactos ambientais mais significativos e com consequências mais nocivas ao meio ambiente (CEF, 2005).

Levy (2017) considera a reciclagem dos RCDs como uma solução para a conservação dos recursos naturais não renováveis extraídos pelo setor da construção civil. A substituição de agregados naturais, como a areia e a brita, por agregados reciclados, tem sido estudada e aplicada para atender às necessidades da indústria da construção. A preservação dos recursos naturais, substituídos por materiais reciclados, prolonga a vida útil das reservas naturais e reduz a destruição da fauna, flora e da paisagem. Esta contribuição é importante, mesmo nos casos em que os recursos naturais são abundantes (JOHN, 2015).

A reutilização dos resíduos da construção civil acarreta benefícios da ordem econômica, social e ambiental. A substituição dos materiais convencionais por materiais reciclados resulta em economia na aquisição de matéria-prima e diminuição do consumo de recursos naturais. Com a reciclagem, há ainda a minimização da poluição causada pelos resíduos, redução de enchentes, assoreamento de rios e córregos. É importante destacar que o descarte incorreto ocasiona várias consequências para o ambiente urbano, propiciando o aparecimento de doenças como dengue e febre amarela, sendo, ainda, um chamariz de roedores e insetos. A falta de encaminhamento adequado desses materiais gera prejuízos do ponto de vista do meio ambiente e da qualidade de vida da população, evidenciando ainda mais a necessidade de reaproveitamento.

Sendo um processo sustentável completo que reduz a poluição, preserva as reservas naturais de matéria-prima, acarretam ganhos financeiros, promovendo oportunidades de trabalho e renda, o tratamento e reciclagem dos resíduos da construção civil é de grande importância, pois requer atenção dos órgãos fiscalizadores e a conscientização de empresários do setor que detêm o grande poder de tomar uma decisão de mudança.

Por fim, vale a pena ressaltar que, segundo a ABRELPE (Associação Brasileira de Empresas de Limpeza Pública e Resíduos Especiais), em 2010, o Brasil produz em média 31 milhões de toneladas de resíduos da construção civil (RCC) por ano. Baseado nessa premissa, este trabalho propõe avaliar o efeito da incorporação de resíduos de construção e demolição na resistência de aderência à tração de argamassas de revestimento, buscando revelar a sua viabilidade técnica nesse campo de aplicação.

\section{REVISÃO TEÓRICA}

\section{Resíduos de construção e demolição e impacto ambiental}

A construção civil é uma atividade econômica com efeitos nocivos ao meio ambiente, pois contribui para o esgotamento de recursos naturais, consome altas quantidades de energia, gera poluição do ar, solo e 
água e produz elevado volume de resíduos (CRUZ JUNIOR, 2011). Além disso, a indústria da construção civil se caracteriza pela ausência de disposição adequada de resíduos ao longo das diferentes etapas do processo produtivo (PINTO, 2017).

Os resíduos de construção e demolição (RCDs) são partes integrantes dos resíduos sólidos urbanos (RSU), e representam, atualmente, um dos maiores problemas para o saneamento ambiental. Esses resíduos são provenientes dos serviços de infraestrutura, como terraplanagem e redes de serviços públicos (água, esgoto, pluvial, gás, energia elétrica e telefônica), e da execução de novas construções urbanas, demolições e reformas de construções existentes (MARQUES NETO, 2015).

No Brasil, a geração contínua e crescente de RCDs está diretamente ligada ao elevado desperdício de materiais na realização dos empreendimentos. Estima-se que, para cada tonelada de lixo urbano recolhido, são coletadas duas toneladas de entulho originado do setor de construção civil. Esse dado alarmante revela a necessidade de políticas de controle, coleta, transporte e disposição final, que viabilizem o emprego do RCD reciclado proveniente de resíduos de construção e demolição como matéria prima na confecção de novos materiais (VENTURINI, 2014).

Todas as etapas do processo construtivo causam impactos ambientais, extração de matéria-prima, produção de materiais, construção, utilização e demolição. Um dos aspectos relevantes é a redução do desperdício na fabricação de materiais e componentes, nas fases de execução dos empreendimentos e após seu término. A reutilização de materiais, tanto nos canteiros de obras como depois das demolições, deve ser implementada como procedimento de minimização do desperdício. Os processos de reciclagem devem ser desenvolvidos a fim de produzir novos materiais passíveis de uso pelo setor da construção civil (TOZZI, 2016).

As áreas irregulares de descartes, vistas como solução para o destino de pequenos volumes de RCD, e o esgotamento dos 'bota-foras', decorrente do incessante descarte de grandes volumes, resulta em inevitáveis impactos em todo o espaço urbano, como comprometimento da qualidade do ambiente e da paisagem local, ocasionando prejuízos nas condições de tráfego de pedestres e veículos, drenagem superficial e obstrução de córregos, multiplicação de vetores de doenças e outros efeitos (LEVY, 2017).

Segundo Marques Neto (2015), reduzir o impacto ambiental causado pela construção civil é tarefa complexa, sendo necessário agir em várias frentes de maneira combinada e simultânea, como: minimizar o consumo de recursos; maximizar a reutilização de recursos; utilizar recursos renováveis ou recicláveis; criar ambiente saudável e não tóxico; e buscar a qualidade na criação do ambiente construído.

A NBR 15113 (ABNT, 2004), tomando como base a resolução do CONAMA nํ307/2002, define os Resíduos Sólidos da Construção e da Demolição (RCDs) como os resíduos provenientes de construções, reformas, reparos e demolições de obras da Construção Civil, assim como também os resultantes da preparação e da escavação de terrenos, tais como tijolos, blocos cerâmicos, concreto em geral, solos, rochas, metais, resinas, colas, tintas, madeiras e compensados, forros, argamassa, gesso, telhas, pavimento asfáltico, vidros, plásticos, tubulações, fiação elétrica, etc.. (CRUZ JUNIOR, 2011).

Segundo Zordan (2012), os agregados provenientes da reciclagem de RCD podem ser usados em argamassas de assentamento de tijolos e blocos ou em revestimentos internos e externos (chapisco, emboço 
e reboco). As vantagens dessa utilização podem ser observadas nos próprios canteiros de obras, pela redução dos custos de transportes, e do consumo de cimento e cal.

\section{Aderência das argamassas de revestimento}

Rosello (1976) conceitua a aderência como a resistência da argamassa de suportar as tensões normais nela exercida, ou tangenciais à superfície da interface com a base. Também afirma que é necessário que a capacidade da alvenaria resista a cargas excêntricas, transversais ou de flambagem, para que haja uma boa homogeneidade de materiais de acabamento ao substrato. A aderência no estado endurecido vai depender muito de outra propriedade das argamassas de revestimento no estado fresco: a adesão inicial.

No sistema de revestimento, a aderência é uma das propriedades mais importantes para o desempenho final. Segundo Carasek (1996), Candia (1998) e Scartezini (2002), a resistência de aderência à tração, essencialmente mecânica, é influenciada principalmente pelo processo de execução, pelas características das argamassas e dos substratos, e pelas trocas de umidade (argamassa-substrato).

Scartezini (2002) observou, nos estudos realizados, uma alta variabilidade no ensaio de determinação da resistência de aderência à tração, apontando vários fatores que podem influenciar nas suas características, tais como: Mão de obra especializada (pedreiro); O tempo em que se esperou para execução do sarrafeamento sendo um fator subjetivo, dependendo necessariamente da habilidade do pedreiro; Tipo de substrato, no qual a microestrutura dos poros é diferente para cada caso, prejudicando o coeficiente de absorção de água da argamassa; e a granulometria dos agregados e o tipo de argamassa utilizada, onde argamassas com maior teor de finos minimizam a sucção do substrato e o preenchimento dos poros pelos produtos da hidratação, reduzindo a adesão inicial.

\section{MATERIAIS E MÉTODOS}

Os materiais empregados na pesquisa são: Cimento Portland composto com pozolana CP II-Z 32; Agregado miúdo natural de origem quartzosa (areia grossa); Água; e Resíduos de construção e demolição (agregados reciclados). 0 traço escolhido para a camada de emboço (revestimento) foi de 1:5 (cimento: areia média e/ou agregado reciclado). Foram utilizados três tipos de agregados miúdos reciclados (cerâmica; cimentício; e misturado: cerâmica e cimentício), empregando os teores de substituição ilustrados na tabela 1.

Tabela 1: Teores de Substituição.

\begin{tabular}{|c|c|c|c|c|}
\hline Traço & Agregados Reciclados Cerâmicos & Agregados Reciclados Cimentícios & Agregados Reciclados Misturados & AREIA \\
\hline REF & $0 \%$ & $0 \%$ & $0 \%$ & $100 \%$ \\
\hline CE25 & $25 \%$ & $0 \%$ & $0 \%$ & $75 \%$ \\
\hline CE50 & $50 \%$ & $0 \%$ & $0 \%$ & $50 \%$ \\
\hline $\mathrm{Cl} 25$ & $0 \%$ & $25 \%$ & $0 \%$ & $75 \%$ \\
\hline $\mathrm{Cl50}$ & $0 \%$ & $50 \%$ & $0 \%$ & $50 \%$ \\
\hline $\mathrm{CI75}$ & $0 \%$ & $75 \%$ & $0 \%$ & $25 \%$ \\
\hline $\mathrm{Cl} 100$ & $0 \%$ & $100 \%$ & $0 \%$ & $0 \%$ \\
\hline M25 & $0 \%$ & $0 \%$ & $25 \%$ & $75 \%$ \\
\hline M50 & $0 \%$ & $0 \%$ & $50 \%$ & $50 \%$ \\
\hline
\end{tabular}




\section{Coleta e preparação dos agregados reciclados}

Foram coletados $600 \mathrm{~kg}$ de amostra de RCD em um terreno baldio, conforme se vê na figura 1, localizado na cidade de Porto Nacional (TO), a qual foi encaminhada para o laboratório de materiais do ITPAC -PORTO. A coleta aconteceu em um só local para diminuir a variabilidade na composição, sob o risco de alterações no resultado final.
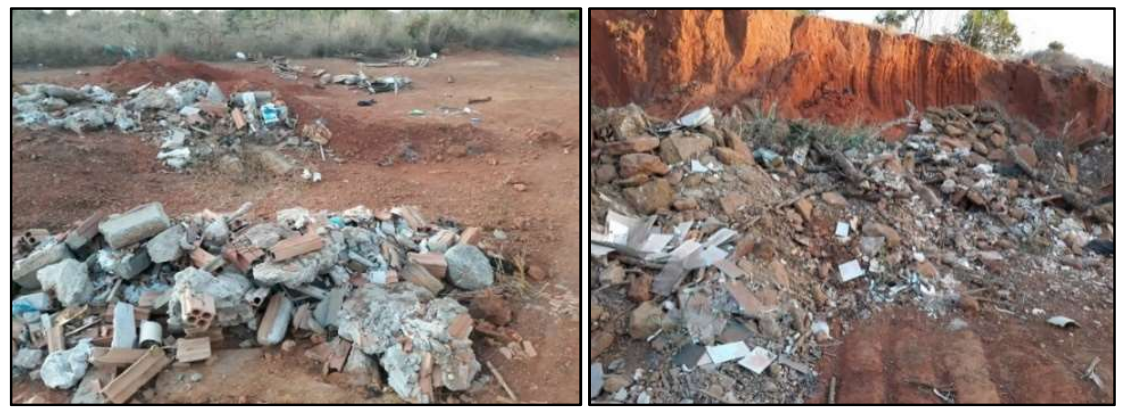

Figura 1: Resíduos da construção e demolição.

As coletas foram realizadas no Setor Universitário Jardins dos Ypês, e como demostra a figura 1, continham materiais como madeira, tintas, telha, pisos, concreto, borracha e plástico. No local da coleta, já foi feita a separação dos materiais e levado ao laboratório apenas resíduos cerâmicos e cimentícios. No laboratório, o material foi quebrado em pedaços menores de forma manual com uso de marretas, e depois submetido à desagregação nas mandíbulas do britador mecânico. Para obter uma granulometria mais fina, foi necessário encaminhar os materiais (separadamente) para a moagem na máquina de abrasão 'Los Angeles'.

A utilização de peneiras de malhas com aberturas de 4,8 e 2,4mm auxiliou no acerto da granulometria, a fim de obter grãos característicos de agregado miúdo. Para obtenção do agregado miúdo reciclado misturado, utilizou-se uma proporção de 50\% de agregados reciclados cerâmicos e $50 \%$ de agregados reciclados cimentícios já previamente moídos e com módulo de finura exato, como mostra a figura 2. O Cimento utilizado foi o CP II-Z 32, com menor custo e o mais utilizado na região de Porto Nacional. As características físicas do cimento estão indicadas na tabela 2.

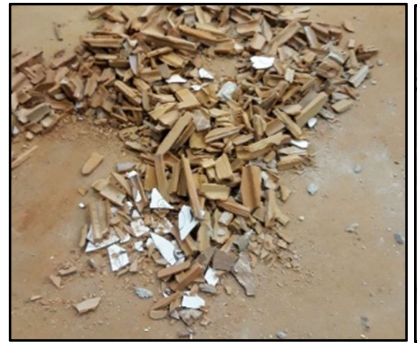

(A)

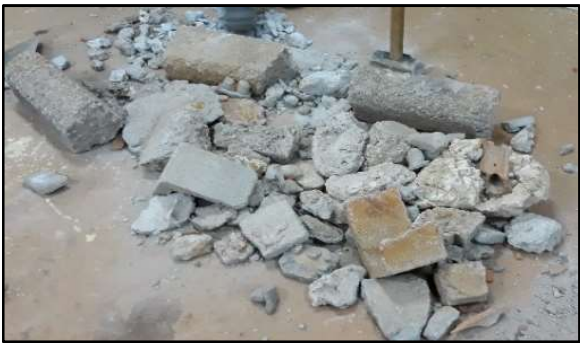

(B)

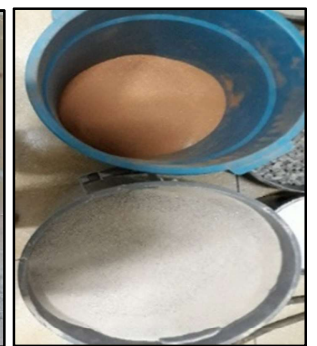

(C)

Figura 2: Agregados reciclados: A) Cerâmicos; B) cimentícios; e C) Material caracterizado e moído.

Tabela 2: Características físicas do cimento.

\begin{tabular}{|c|c|}
\hline Característica física & CP II Z 32 \\
\hline Massa específica (NBR NM 23) & $2,9\left(\mathrm{~g} / \mathrm{cm}^{3}\right)$ \\
\hline Início de pega (NBR NM 65) & $280(\mathrm{~min})$ \\
\hline Fim de pega (NBM NM 65) & $375(\mathrm{~min})$ \\
\hline Finura (MB 3432) & $7,003(\%)$ \\
\hline Resistência à compressão aos 28 dias (NBR 7215) & $32(\mathrm{MPa})$ \\
\hline
\end{tabular}




\section{Agregados}

As dimensões obtidas para os agregados estão de acordo com a NM 248 (ABNT, 2003). Foram realizados ensaios de massa específica, massa unitária e o ensaio de composição granulométrica para os agregados naturais e reciclados, do qual foram obtidas as curvas granulométricas, módulo de finura (MF), e dimensão máxima dos agregados. Os resultados dos ensaios de caracterização são apresentados na tabela 3.

Tabela 3: Características físicas dos agregados.

\begin{tabular}{|c|c|c|c|c|c|}
\hline Agregados & $\begin{array}{c}\text { Módulo de } \\
\text { Finura } \\
\text { (NBR 7217) }\end{array}$ & $\begin{array}{c}\text { Dimensão Máxima } \\
\text { Característica } \\
\text { (NBR 7217) }\end{array}$ & $\begin{array}{c}\text { Zona } \\
\text { Granulométrica }\end{array}$ & $\begin{array}{c}\text { Massa Específica (NM } \\
\text { 52) }\end{array}$ & $\begin{array}{c}\text { Massa Unitária (MN } \\
\text { 45) }\end{array}$ \\
\hline $\begin{array}{c}\text { Areia } \\
\text { Natural }\end{array}$ & 3,01 & 4,8 & Areia Grossa & $2,63 \mathrm{~g} / \mathrm{cm}^{3}$ & $1,62 \mathrm{~g} / \mathrm{cm}^{3}$ \\
\hline Cerâmico & 3,25 & 4,8 & Areia Grossa & $2,44 \mathrm{~g} / \mathrm{cm}^{3}$ & $1,31 \mathrm{~g} / \mathrm{cm}^{3}$ \\
\hline Cimentício & 2,12 & 2,4 & Areia Média & $2,36 \mathrm{~g} / \mathrm{cm}^{3}$ & $1,01 \mathrm{~g} / \mathrm{cm}^{3}$ \\
\hline Misturado & 2,34 & 2,4 & Areia Média & $2,39 \mathrm{~g} / \mathrm{cm}^{3}$ & $1,02 \mathrm{~g} / \mathrm{cm}^{3}$ \\
\hline
\end{tabular}

\section{Execução do revestimento}

Funcionando como substrato, foram levantadas três paredes de $1,70 \times 1,20 \mathrm{~m}$, em ambiente externo (expostas ao sol e à chuva), utilizando blocos cerâmicos de vedação de 6 furos com dimensões 9X14X19cm, como podemos observar na figura 3. Chapisco de consistência bem fluída, com traço 1:4 (cimento, areia grossa), foi aplicado sob a superfície para melhorar a aderência do futuro revestimento.

A proporção dos materiais empregados para confecção das argamassas de emboço (revestimento) seguiu o traço de 1:5 em massa (cimento: agregado). Esta proporção é muito utilizada na região. A relação água/materiais secos foi variável para cada argamassa, sendo ajustada para que atingir índice de consistência de $26 \pm 1 \mathrm{~cm}$.

Todo o preparo das argamassas tiveram seus tempos controlados e executados da seguinte forma: misturaram-se os materiais secos (cimento e agregado miúdo) em betoneira de eixo inclinado por 1 minuto, a fim de se obter homogeneização; adicionou-se 50\% da água e misturou-se por mais 30 segundos; fez-se pausa de 50 segundos para homogeneização de possíveis materiais no fundo da cuba da betoneira; misturouse por mais 1 minuto adicionando-se o restante da água fracionadamente.

A adição de água na mistura foi feita de forma fracionada, pois estudos concluem que esse método confere à argamassa melhores propriedades como maior resistência ao cisalhamento, além de que, a adição da água de forma fracionada gera maior eficiência na mistura e maior homogeneidade e desaglomeração da mistura, tornando-a, assim, mais fácil de ser aplicada. A relação água/materiais secos foi determinada para cada argamassa a fim de se obter aproximadamente a mesma trabalhabilidade para todas. A tabela 4 mostra o consumo de materiais utilizados.

Tabela 4: Consumo de materiais.

\begin{tabular}{|c|c|c|c|c|}
\hline \multicolumn{5}{|c|}{ Consumo de Materiais } \\
\hline Traço & Cimento (kg) & Areia $(\mathrm{kg})$ & Agregado reciclado (kg) & Água(L) \\
\hline REF & 10 & 50 & 0 & 13 \\
\hline CE25 & 10 & 37,5 & 12,5 & 15 \\
\hline CE50 & 10 & 25 & 25 & 13 \\
\hline $\mathrm{Cl} 25$ & 10 & 37,5 & 12,5 & 13 \\
\hline $\mathrm{Cl50}$ & 10 & 25 & 25 & 12 \\
\hline $\mathrm{Cl75}$ & 10 & 12,5 & 37,5 & 14 \\
\hline
\end{tabular}




\begin{tabular}{|l|c|c|c|c|}
\hline Cl100 & 10 & 0 & 50 & 14 \\
\hline M25 & 10 & 37,5 & 12,5 & 25 \\
\hline M50 & 10 & 25 & 13 & 13 \\
\hline
\end{tabular}

Após 72 horas de cura do chapisco (molhando com mangueira), as paredes foram novamente umedecidas para uniformizar a absorção de água, e os traços de argamassa do emboço (revestimento) foram aplicados, com espessura de 2cm, seguindo as normas da NBR 7200 (ABNT, 1997). Os painéis de emboço foram molhados continuamente por três dias, sempre que sua superfície secava, a fim de minimizar a perda de água (região de clima muito quente), auxiliar nas reações de hidratação, e prevenir fissuração precoce das argamassas. Os ensaios de aderência à tração foram executados na idade $28 \pm 2$ dias após execução dos painéis de revestimento.

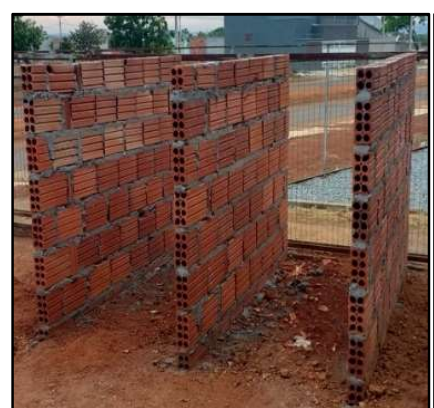

A)

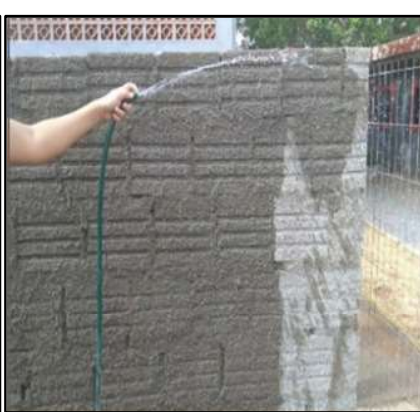

(B)

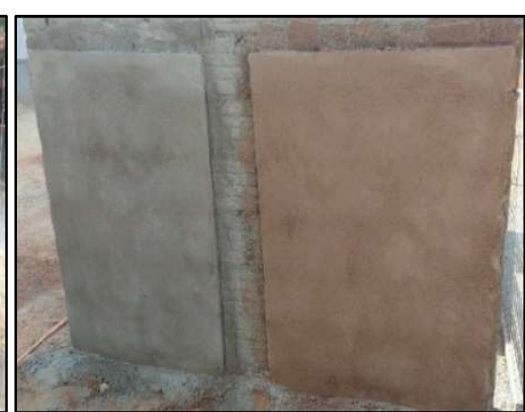

(C)

Figura 3: A) Paredes de alvenaria; B) Cura do chapisco; C) Traço REF e CE25\%.

\section{Ensaio de resistência de aderência à tração}

As argamassas no estado endurecido devem apresentar uma boa resistência de aderência à tração resistindo às tensões atuantes na interface com o substrato. A NBR 13749 (ABNT, 1996) estabelece que o valor mínimo de resistência de aderência à tração para emboço e camada única aplicados sobre paredes cerâmicas é de 0,30Mpa. Para averiguar a viabilidade da incorporação de resíduos de construção e demolição, analisou-se a resistência de aderência de argamassas de revestimento aos 28 dias de idade, executando 9 traços de argamassas com diferentes teores de substituição. Nesse experimento foi utilizado um equipamento dinamômetro de tração, previamente calibrado como é mostrado na figura 4.

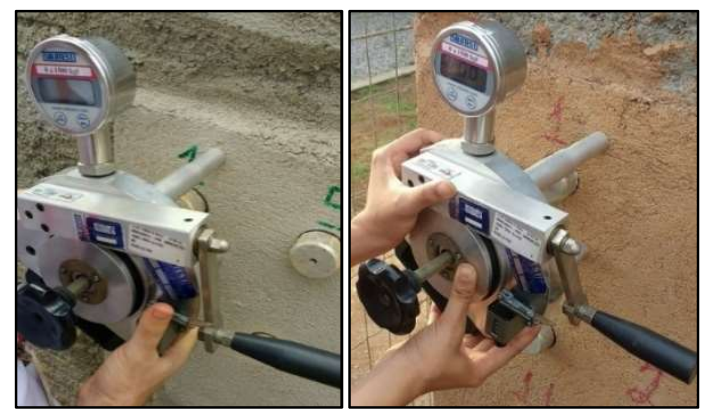

Figura 4: Equipamento dinamômetro de tração.

\section{Arrancamento dos corpos de prova}

Em cada painel, foi realizado o ensaio de determinação da resistência de aderência à tração, respeitando as recomendações técnicas da NBR 13528 (ABNT, 2010). O espaçamento utilizado entre cada 
corte foi em média de $20 \mathrm{~cm}$ e cada corte foi numerado aleatoriamente afim de identificar cada corpo de prova.

Foi utilizado um dispositivo de corte (serra copo) circular de $50 \mathrm{~mm}$ de diâmetro acoplado a uma furadeira para fazer o corte a seco na argamassa de revestimento. Em seguida, a colagem das partilhas metálicas foi feita utilizando cola à base de resina poliéster, com secagem rápida de 20 minutos. 0 corte úmido não foi executado devido à formação de um filme de água superficial que tende reduzir a resistência de aderência entre os materiais de base cimentícia, interferindo nos resultados (BONALDO et al., 2005).

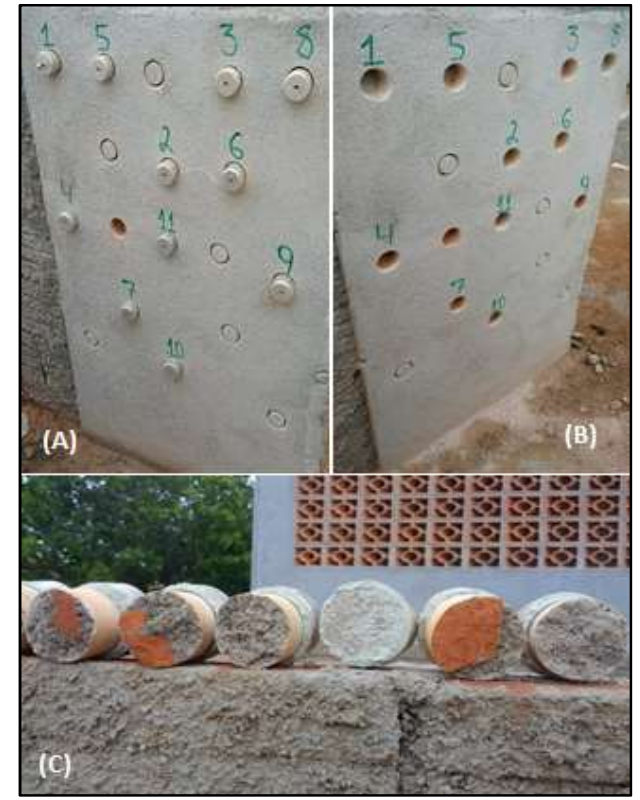

Figura 5: A) Pastilhas coladas no painel; B) Furos após o arrancamento; C) Corpos de prova.

O material empregado para colar as partilhas apresentou um bom desempenho. No entanto, como podemos verificar na figura 5 , surgiram problemas no momento das rupturas. Vários corpos de prova apresentaram ruptura no substrato (cerâmica), ou romperam apenas com o peso próprio do equipamento, razão pela qual algumas rupturas tiveram que ser refeitas em outros pontos dos painéis para obter resultados suficientes. Costa et al. (2009) afirma que, por vezes, ocorrem alterações por conta do encaixe da peça levando a tensões laterais no corpo de prova antes mesmo da execução do ensaio ou excentricidade quando este é realizado.

Devido ao clima quente (acima de $30^{\circ} \mathrm{C}$ ), mesmo com os cuidados de cura, algumas argamassas fissuraram. Os painéis que apresentaram fissuras foram os contendo RCDs na sua composição, os traços com $50 \%$ e $100 \%$ de agregados reciclados cimentícios, e os traços com $25 \%$ e $50 \%$ de agregados reciclados misturados. No Apêndice A se encontram os resultados dos 12 arrancamentos para todos os traços.

\section{RESULTADOS E DISCUSSÃO}

A figura 6 mostra a resistência média de todos os traços. Como é possível verificar na figura 8, o consumo de água para cada traço variou entre 12 a 15 litros, sendo que o traço CE25 foi o que necessitou de maior quantidade de água para atingir a consistência desejada de aplicação, e no traço Cl50 tem-se o menor consumo de água. Isso indica que o consumo de água pode ter influenciado diretamente na resistência final 
dos traços com agregados reciclados, onde os traços com menor consumo de água apresentaram maiores resistências à tração (figura 6), com exceção do traço CE25, evidenciando o potencial de retenção de água do agregado miúdo cerâmico e sugerindo a presença de reações pozolânicas, uma vez que manteve resistência próxima do traço de referência.

Pissolato Junior (2016) observou a influência da retenção de água na resistência de aderência, pois essa propriedade evita que a argamassa perca água por evaporação em contato com o substrato. A retenção de água nos traços de argamassa hidráulica com agregado reciclado apresentou uma tendência, isto é, quanto mais incorporou-se agregado à mistura, maior foi a retenção de água.

A NBR 13749 (ABNT, 1996) limita o desvio padrão para os resultados de resistência de aderência à tração aos 28 dias em 0,11Mpa. Por meio do gráfico apresentado na figura 7 é possível observar que os resultados da maioria dos traços ficaram dentro do desvio padrão permitido, com exceção do traço $\mathrm{Cl} 100$, que apresentou um desvio padrão de 0,13Mpa, e o traço CE25 que apresentou um desvio padrão de 0,12Mpa. Os menores desvios padrão ocorreram nos resultados obtidos nos traços $\mathrm{M} 25$ e $\mathrm{Cl} 75$, respectivamente, com valores de 0,02 e 0,03 $\mathrm{MPa}$ (maior confiabilidade nos resultados).

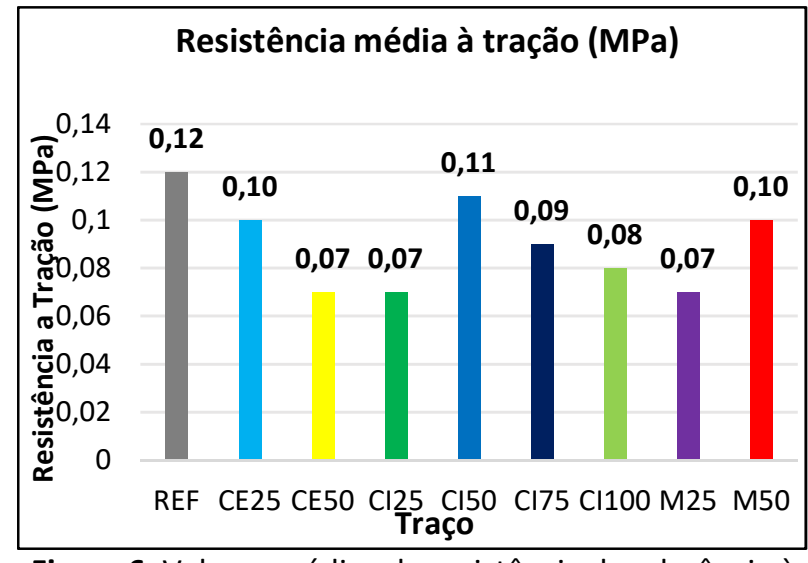

Figura 6: Valores médios de resistência de aderência à tração, cortes a seco aos 28 dias.

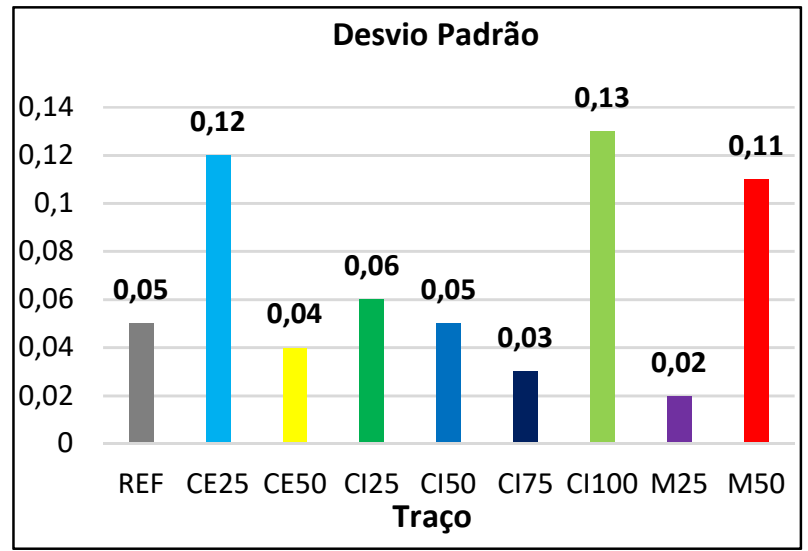

Figura 7: Desvio padrão dos resultados aos 28 dias

De acordo com Bonaldo et al. (2005), a utilização de um único equipamento proporciona uma alta variabilidade, onde ao mesmo tempo em que se apresentam valores baixos, surgem valores elevados. Costa et al. (2009) ressalta que o corte realizado com água proporciona menor variabilidade em relação ao corte executado a seco, pois o mesmo está relacionado com a redução de vibrações do corpo de prova no decorrer da execução. A figura 7 demostra os valores de desvio padrão dos resultados obtidos aos 28 dias. A figura 8 mostra o consumo de água em litros de todos os traços.

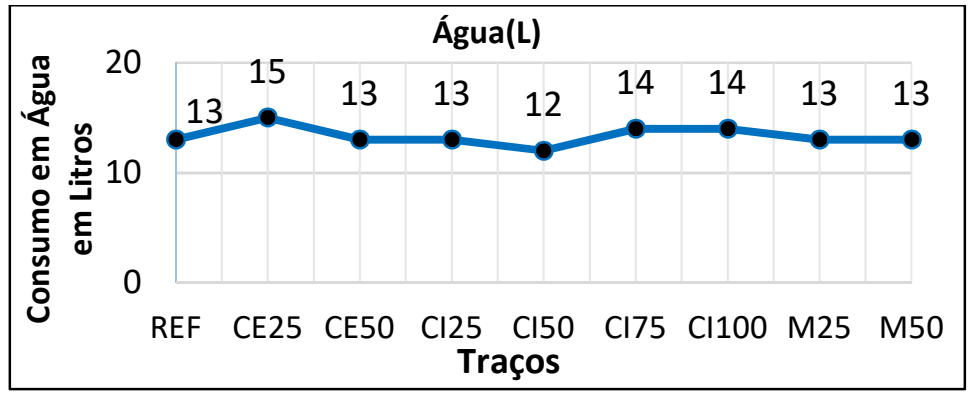

Figura 8: Consumo de água. 
Através dos resultados médios, a resistência à tração, apresentada na figura 6, pode-se constatar que nenhum dos traços atingiu a resistência mínima especificada pela norma aos 28 dias $(\geq 0,30 \mathrm{MPa})$, nem mesmo o traço de referência. Girardi (2016) também estudou o comportamento da argamassa produzida com agregado reciclado em substituição ao agregado natural. No trabalho de Girardi (2016), foram utilizados três tipos de agregados: areia natural lavada quartzosa de rio (para execução do traço de referência); agregado reciclado misto de cerâmica e material cimentício e agregado reciclado cimentício, sendo os dois últimos provenientes de duas indústrias de reciclagem da região metropolitana de Goiânia (GO).

O valor máximo para resistência de aderência à tração encontrada foi de 0,19Mpa, também abaixo do mínimo exigido pela norma. De acordo com Girardi (2016), a interação entre as partículas, especialmente o fator de empacotamento, são as propriedades que apresentam maior correlação com o desempenho dos revestimentos, e deverão ser avaliadas na escolha do agregado reciclado.

Também foi possível observar que os resultados variaram muito, não apresentando um comportamento linear, e todos os traços contento agregados reciclados apresentaram menores resistências médias do que o traço de referência. Na pesquisa de Oliveira et al. (2011), como o aumento da resistência também não se apresentou de forma linear, Oliveira et al. (2011) estudou um teor ótimo de agregado a ser utilizado na mistura. Eles concluíram que a substituição de $37,2 \%$ da areia natural por RCD gera um maior acréscimo na resistência de aderência à tração.

Os traços contendo agregado miúdo reciclado de cerâmica e agregado miúdo reciclado misturado tiveram comportamentos opostos. Nos traços com cerâmica, quanto maior o teor de substituição (25 a $50 \%)$, menor a resistência de aderência à tração, enquanto que, nos traços contendo agregado misturado, quanto maior o teor de substituição (25 a 50\%), maior a resistência de aderência à tração. Esse efeito pode ser explicado pela presença de agregado cimentício na composição do agregado misturado, uma vez que a maior resistência entre os traços com agregados reciclados foi obtida pelo traço contendo $50 \%$ de agregado cimentício (Cl50), que atingiu 0,11MPa. O resíduo cerâmico pode ter comprometido mais a resistência em função de sua elevada granulometria, dificultando a adesão inicial.

A resistência obtida pelo traço de referência foi de $0,12 \mathrm{MPa}$, e os traços com melhores resultados foram Cl50, CE25 E M50, com resistências de 0,11Mpa, 0,10MPa e 0,10MPa, respectivamente, evidenciando a necessidade de estudos mais aprofundados e testes com outros intervalos de substituição para chegar a conclusões mais confiáveis. Os traços CE50, Cl25 e M25 apresentaram as menores resistências.

Esses resultados seguem a tendência de variação observada nos trabalhos de outros autores. Serra et al. (2014), ao analisar a resistência potencial de aderência à tração com incremento de 75\% de resíduo, obtiveram uma argamassa que se apresentou mais resistente com a adição de agregados reciclados quando comparada com a argamassa produzida com agregado natural. Um estudo desenvolvido por Oliveira et al. (2011) com cinco traços contendo diferentes teores de agregado reciclado (10\%, $20 \%, 30 \%, 40 \%$ e $50 \%)$, revelou valores de resistência à tração superiores aos exigidos pela NBR 13749 (ABNT, 1996). Além disso, observou-se que quanto maior o teor de agregado reciclado, maior foi a resistência de aderência à tração, exceto para os traços com $30 \%$ e $50 \%$ de substituição. 
Já Pissolato Junior (2016), ao estudar o comportamento de argamassa produzida com agregado reciclado, utilizou três traços de substituição de agregado natural, pelo agregado de RCD: $30 \%, 60 \%$ e $100 \%$. Todos os resultados mostram-se abaixo dos valores exigidos pela norma, e o melhor desempenho foi obtido com $30 \%$ de substituição, que apresentaram valores de resistência acima de 0,2MPa.

\section{CONCLUSÕES}

Analisando todos os resultados, observamos que as porcentagens de substituição de agregado reciclado que obtiveram melhor desempenho, foram de 50\% de agregado reciclado cimentício, com resistência média de 0,11Mpa; de 25\% de agregado reciclado cerâmico, com resistência média de 0,10Mpa; e a de $50 \%$ de agregado reciclado misturado, com uma resistência média de 0,10MPa, todos com 28 dias de cura. Os demais traços tiveram resistência de aderência à tração entre 0,07MPa e 0,09MPa.

O trabalho experimental não alcançou a resistência mínima estipulada pela NBR 13749 (ABNT, 1996), e as pesquisas de outros autores mostraram também resultados contraditórios, portanto, sugerimos que em trabalhos futuros sejam realizados ensaios com outros teores de substituições para comparar os efeitos da incorporação dos agregados, que seja utilizada uma mão de obra mais especializada, e que o ensaio de aderência seja realizado com cautela a fim de evitar vibrações que possam interferir nos resultados. As vantagens da reutilização de resíduos tornam vital certificar a sua viabilidade e estabelecer parâmetros de dosagem.

\section{REFERÊNCIAS}

ABNT. Associação Brasileira de Normas Técnicas. NBR 115811 NM 65: Cimento portland - Determinação do tempo de pega. Rio de Janeiro: ABNT, 2003.

ABNT. Associação Brasileira de Normas Técnicas. NBR 13528: Revestimento de paredes e tetos de argamassas inorgânicas: Determinação da resistência de aderência à tração. Rio de Janeiro: ABNT, 2010.

ABNT. Associação Brasileira de Normas Técnicas. NBR 13749: Revestimento de paredes e tetos de argamassas inorgânicas: Especificação. Rio de Janeiro: ABNT, 1999.

ABNT. Associação Brasileira de Normas Técnicas. NBR 15113: Resíduos sólidos da construção civil e resíduos inertes: Aterros: Diretrizes para projeto, implantação e operação. Rio de Janeiro: ABNT, 2006.

ABNT. Associação Brasileira de Normas Técnicas. NBR 6474 NM 23: Cimento Portland e outros materiais em pó: Determinação da massa específica. Rio de Janeiro: ABNT, 2001.

ABNT. Associação Brasileira de Normas Técnicas. NBR 7200: Execução de revestimento de paredes e tetos de argamassas inorgânicas: Procedimento. Rio de Janeiro: ABNT, 1998.

ABNT. Associação Brasileira de Normas Técnicas. NBR 7215: Cimento Portland: Determinação da resistência à compressão. Rio de Janeiro: ABNT, 1996.
ABNT. Associação Brasileira de Normas Técnicas. NBR 7217: Agregados: determinação da composição granulométrica. Rio de Janeiro: ABNT, 1987.

ABNT. Associação Brasileira de Normas Técnicas. NBR MB 3432: Cimento Portland: Determinação da finura por meio da peneira $75 \mu \mathrm{m}$ (no 200). Rio de Janeiro: ABNT, 1991.

ABNT. Associação Brasileira de Normas Técnicas. NBR NM 45: Agregados: Determinação da massa unitária e do volume de vazios. Rio de Janeiro: ABNT, 2006.

ABNT. Associação Brasileira de Normas Técnicas. NBR NM 52: Agregado miúdo: Determinação da massa específica e massa específica aparente. Rio de Janeiro: ABNT, 2003.

ABNT. Associação Brasileira de Normas Técnicas. NM 248 Agregados: Determinação da composição granulométrica. Rio de Janeiro: ABNT, 2003.

BONALDO, E.; BARROS, J.; LOURENÇO, P.. Bond Characterization Between Concrete Substrate and Repairing SFRC Using Pull-Off Testing. International Journal of Adhesion \& Adhesives, v.25, n.6, p.463-474, 2005.

CANDIA, M. C.; FRANCO, L. S.. Contribuição ao Estudo das Técnicas de Preparo da Base no Desempenho dos Revestimentos de Argamassa. São Paulo: EPUSP, 1998.

CARASEK, H.. Aderência de argamassas à base de cimento Portland a substratos porosos: Avaliação dos fatores 
intervenientes e contribuição ao estudo do mecanismo da ligação. Tese (Doutorado em Engenharia Civil) - Universidade de São Paulo, São Paulo, 1996.

CEF. Caixa Econômica Federal. Manejo e gestão de resíduos da construção civil. Brasília: CEF, 2005.

CONAMA. Conselho Nacional do Meio Ambiente. Resolução n.307 de 5 de julho de 2002. Brasília: CONAMA, 2002.

COSTA, E. B.; CARASEK, H.. Influência dos parâmetros de ensaio na determinação da resistência de aderência de revestimentos de argamassa. Porto Alegre: 2009.

CRUZ JUNIOR, J. B.. Análise da gestão de resíduos sólidos da construção e da demolição (RCDs) de Angicos. Monografia (Graduação em Ciência e Tecnologia) - Universidade Federal Rural do Semiárido, Angico, 2011.

GIRARDI, A. C. C.. Avaliação da substituição total de areia natural por RCD em revestimentos de argamassa.

Dissertação (Mestrado em Geotecnia) - Universidade Federal de Goiás, Goiânia, 2016.

GONÇALVES, S. R. C.. Variabilidade e fatores de dispersão da resistência de aderência nos revestimentos em argamassa: Estudo de caso. Brasília: 2004.

JOHN, V. M.. Reciclagem de resíduos na construção civil: contribuição para metodologia de pesquisa e desenvolvimento. Tese (Livre Docência) - Universidade de São Paulo, São Paulo, 2015.

LEVY, S. M.. Reciclagem do entulho da construção civil, para utilização como agregados para argamassa e concreto. Dissertação (Mestrado) - Universidade de São Paulo, São Paulo, 2017.

MARQUES NETO, J. C.. Gestão dos resíduos de construção e demolição no Brasil. São Carlos: RiMa: 2015.

OLIVEIRA, M. E. D.; CABRAL, BEZERRA, A. E.. Argamassas de revestimento produzidas com agregados reciclados de
Fortaleza/CE, Brasil. Engenharia Civil, Fortaleza, v.41, n.41, p.21-34, 2011.

PINTO, T. P.. Metodologia para a gestão diferenciada de resíduos sólidos da construção urbana. Tese (Doutorado em Construção Civil) - Universidade de São Paulo, São Paulo, 2017.

PISSOLATO JUNIOR, O.. Argamassa de revestimento utilizando areia proveniente de britagem de resíduo de construção civil. Dissertação (Mestrado em Sistemas de Infraestrutura Urbana) - Pontifícia Universidade Católica, Campinas, 2016

ROSELLO, M. T. V.. Morteros de cemento para albañilería. Madrid: Instituto Eduardo Torroja de la Construcción y del Cemento, 1976.

SCARTEZINI, L. M.. Influência do Tipo e Preparo do Substrato na Aderência dos Revestimentos de Argamassa: Estudo da Evolução ao Longo do Tempo, Influência da Cura e Avaliação da Perda de Água da Argamassa Fresca. Dissertação (Mestrado em Mestrado em Engenharia Civil) Universidade Federal de Goiás, Goiânia, 2002.

SERRA, J. H. F.; SANTANA, L. B.; CABRAL, A. E. B.. Avaliação da reutilização de agregados reciclados de argamassa na produção de emboço. In: ENCONTRO NACIONAL DE TECNOLOGIA DO AMBIENTE CONSTRUÍDO. Anais. Maceió: 2014.

TOZZI, R. F.. Estudo da influência do gerenciamento na geração dos resíduos de construção civil (RCC): estudo de caso de duas obras em Curitiba/PR. Dissertação (Mestrado) Universidade Federal do Paraná, Curitiba, 2016.

VENTURINI, M. M. A.. Gerenciamento de resíduos da construção civil baseado na gestão adotada pela prefeitura municipal de Belo Horizonte. Monografia (Especialização em Construção Civil) - Universidade Federal de Minas Gerais, Belo Horizonte, 2014.

ZORDAN, S. E.. Entulho na indústria da construção. São Paulo: EPUSP, 2012.

A CBPC - Companhia Brasileira de Produção Científica (CNPJ: 11.221.422/0001-03) detém os direitos materiais desta publicação. Os direitos referem-se à publicação do trabalho em qualquer parte do mundo, incluindo os direitos às renovações, expansões e disseminações da contribuição, bem como outros direitos subsidiários. Todos os trabalhos publicados eletronicamente poderão posteriormente ser publicados em coletâneas impressas sob coordenação da Sustenere Publishing, da Companhia Brasileira de Produção Científica e seus parceiros autorizados. Os (as) autores (as) preservam os direitos autorais, mas não têm permissão para a publicação da contribuição em outro meio, impresso ou digital, em português ou em tradução. 